\title{
Institutional Assessment and the Intellectual Work of Teaching and Learning in First-Year Composition
}

\author{
Emily Donnelli-Sallee, PhD \\ Associate Professor of English \\ Park University
}

\begin{abstract}
Institutional assessment initiatives can provide opportunities to make the intellectual work of teaching and learning in composition studies more visible. Reciprocally, the scholarship of teaching and learning's situatedness within disciplinary norms and values can enhance institutional assessments, providing a check on the tendency to rely on singular, overly generalized mechanisms for capturing course- or program-level data. This article shares one example of the reciprocal relationship that can occur between disciplinary and institutional assessment initiatives.
\end{abstract}

Given the role first-year composition courses typically occupy in university general education programs, those of us who direct writing programs are often the first faculty within English departments to be invited to wed our work to institutional assessment. As with any arranged marriage, the "getting to know you" phase can prove quite awkward, and with good reason. Composition's emphasis on writing-asprocess translates into assessments that privilege the qualitative and local, and that often (actively) resist the quantitative and generalizable.

My own experience integrating the portfolio assessment used in my program's first-year writing seminar courses into the University's new learning outcomes manager software was no different than the above characterization - I was deeply skeptical about the happily ever after, about reaping an instructional or intellectual return on investment that would have meaning for the writing program. However, in spite of my skepticism, I found that institutional assessment initiatives can provide valuable opportunities to make the intellectual work of teaching and learning in first-year writing more visible to publics outside of the humanities. Reciprocally, the scholarship of teaching and learning's situatedness within disciplinary norms and values can enhance institutional assessments by providing a check on the tendency to rely on singular, universal mechanisms for capturing course- and program-level data. In this way, my experience bears witness to Huber, Hutchings, and Ciccone's (2011) argument that mutually transformative relationships can occur between the scholarship of teaching and learning and institutional assessment.

\section{Institutional Context}

Park University's first-year writing program consists of two seminar courses, EN 105: Critical Reading, Writing, and Thinking across Contexts, and EN 106: Academic Research and Writing. Both courses are requirements in the University's general education program, and both are taught across all four of the institution's instructional modalities: 16-week face-to-face, eight-week face-to-face, eight-week online, and eight-week blended (where a portion of the instruction, not to exceed $50 \%$, occurs online). Given the multimodal and geographically distributed nature of teaching and learning at Park University, comprising 40 campus centers and a large online program, comparing learner outcomes across instructional modes is key to ensuring curriculum consistency. The use of common course learning objectives, a common summative assessment (for first-year composition, the writing portfolio) and rubric, and common textbooks lends consistency without closing off opportunities for academic freedom. While setting 
the tone and general expectations for a process-oriented writing course, however, these input measures alone cannot adequately answer questions about the comparability of student learning outcomes across the University system.

The University's assessment pilot for general education provided the opportunity to input the assessment materials for these writing courses (the course objectives, summative portfolio assignment, and accompanying rubric) into an outcomes manager software attached to the University's learning management system. Through this process, the portfolio assignment was codified, as was use of the rubric - which, up until this point, had served primarily by example, identifying dimensions of the writing portfolio instructors could attend to when grading: focus, development, organization, technical skill, adaptation to audience, and rhetorical purpose. Via the outcomes manager, the writing portfolio assignment and the rubric criteria moved from the realm of pedagogical suggestion or best practice model to that of institutional directive, with the Office of Academic Assessment tracking use of the outcomes manager rubric as a tool for recording student performance.

\section{Assessment in First-Year Composition and the Scholarship of Teaching and Learning}

In "English Studies in the Scholarship of Teaching and Learning," Salvatori and Donahue (2002) reason that "because of specific historical, economic, and institutional contingencies, composition studies has witnessed a remarkable proliferation of research in writing pedagogy" (p. 70). A significant focus of this inquiry has been in the area of assessment, the resulting scholarship yielding rich and varied results - from research on particular aspects of writing instruction (e.g., Rebecca Moore Howard's work on plagiarism, 2008) to longitudinal studies of the transferability of first-year writing instruction (e.g., Marilyn Sternglass' Time to Know Them, 1992) to entirely new paradigms for assessing writing (e.g., Broad's et al. Dynamic Mapping Criteria, 2009). The scholarship of teaching and learning has also invigorated efforts to document and disseminate the intellectual work of teaching (e.g., Amy Goodburn's work, 1997, on the peer review of teaching in English). In short, the scholarship of teaching and learning in composition studies has remained true to its "originating emphasis on students' writing, student writers, students' learning" (Salvatori \& Donahue, 2002, p. 83). However, what remains to be seen is whether we have framed our inquiry into student learning, and our philosophies and methods for assessment, in ways that prepare us to make our intellectual work understandable to the audiences outside our writing programs.

When I began exploring how the first-year writing program's guidelines for assigning and assessing the writing portfolio could be adapted for the purposes of institutional assessment, I began to realize that despite a shared vision of promoting student learning, the "shapes that [the] impulse to inquiry takes [in the scholarship of teaching and learning] are sometimes far afield from the kind of work that occupies the institution's office of assessment" (Hutchings, Huber, \& Ciccone, 2011, p. 74). Indeed, as Hutchings, Huber, and Ciccone observe, the conflicts that arise between these two perspectives - classroom and institution - are largely rhetorical, a matter of audience (p. 69). Whereas the scholarship of teaching and learning is taken up by faculty to investigate self- or disciplinarily-defined questions, with findings disseminated to insider audiences, assessment typically emanates from administrative needs or requirements with results largely used to defend the value and efficacy of an institution's programs to external stakeholders. Not to be underestimated are the epistemological implications posed by these differing audiences - as well as the related potential for new understandings of teaching, learning, and assessment to be generated as diverse audiences are engaged in dialogue. 


\section{Mapping Course Assessment to Program Outcomes}

The learning objectives and portfolio assessment for our writing program are keyed to disciplinary outcomes, specifically the Council of Writing Program Administrators (WPA) outcomes for first-year composition. Involvement in the University's assessment initiative required alignment of all participating courses with the University's outcomes for general education, called the "literacies" (analytical and critical thinking; community and civic responsibility; scientific inquiry; ethics and values; literary and artistic expression; interdisciplinary and integrative thinking). Mapping the relationships among the objectives of our courses, the WPA outcomes, and the University's literacies forced the program to render in explicit terms how our first-year writing courses directly supported the University's vision of general education (Figure 1, shown on p. 54). In doing so, we uncovered opportunities to revise our learning objectives for the courses in ways that would accentuate the relevance of our discipline (as represented in the WPA outcomes) to the general education aims of the University. The value of our two-course required composition sequence was affirmed, and we were equipped with the language to continue championing the value of our courses. Following Adler-Kassner and O'Neill's admonition, compositionists must position their work "within the larger frames surrounding the academy and education generally... [in order to be] understood as 'legitimate'"' (2010, p. 99).

However, we found that participation in the institutional assessment initiative for general education not only clarified the contributions of the first-year writing program to general education but also revealed needed enhancements to our curriculum and faculty development initiatives in the writing program.

\section{Results and Discussion}

Approximately 88 adjunct instructors teach in the first-year writing program; assisting these instructors with navigation of the learning outcomes software facilitated conversations that extended beyond the software's technical aspects. Instructors had questions to pose and insights to offer about the course objectives, textbooks, and the writing portfolio assessment itself. For instance, some of the field-specific terminology and criteria present in the rubric for the writing portfolio assumed a level of congruity with the WPA outcomes not evident to all of our adjunct instructors, many of whom were trained to teach literature.

The instructors also expressed concerns about the extent to which students could readily interpret the rubric dimensions and criteria. This dialogue helped make sense of the initial round of data pulled from the learning outcomes manager, which showed little variance in student performance within or across rubric dimensions, with the exception of the "technical skill" category, encompassing grammar, mechanics, and documentation (with an $n=546$ students, this was the only rubric dimension with statistically significant variation). Arguably, most instructors perceived that category as the most objective and the criteria most straightforward in explaining "does not meet," "meets," and "exceeds expectations" rankings. As a result, we are currently revising the rubric and creating professional development materials that will better scaffold instructors' use of the rubric to assess the portfolio and, most importantly, to support students' writing processes.

The University's assessment initiative for general education usefully challenged the vision of assessment often generated by the scholarship of teaching and learning in the discipline of composition studies - intensely qualitative, difficult to scale. Those of us in the writing program gained from the experience of translating our descriptive approach into a more prescriptive and ubiquitous tool, as we made sense of the quantitative data that resulted. At the same time, the experience highlighted the need for a more explicit rendering of the norms and nomenclature of assessment in composition, uncovering an important way that the scholarship of teaching and learning productively informs institutional assessment - 

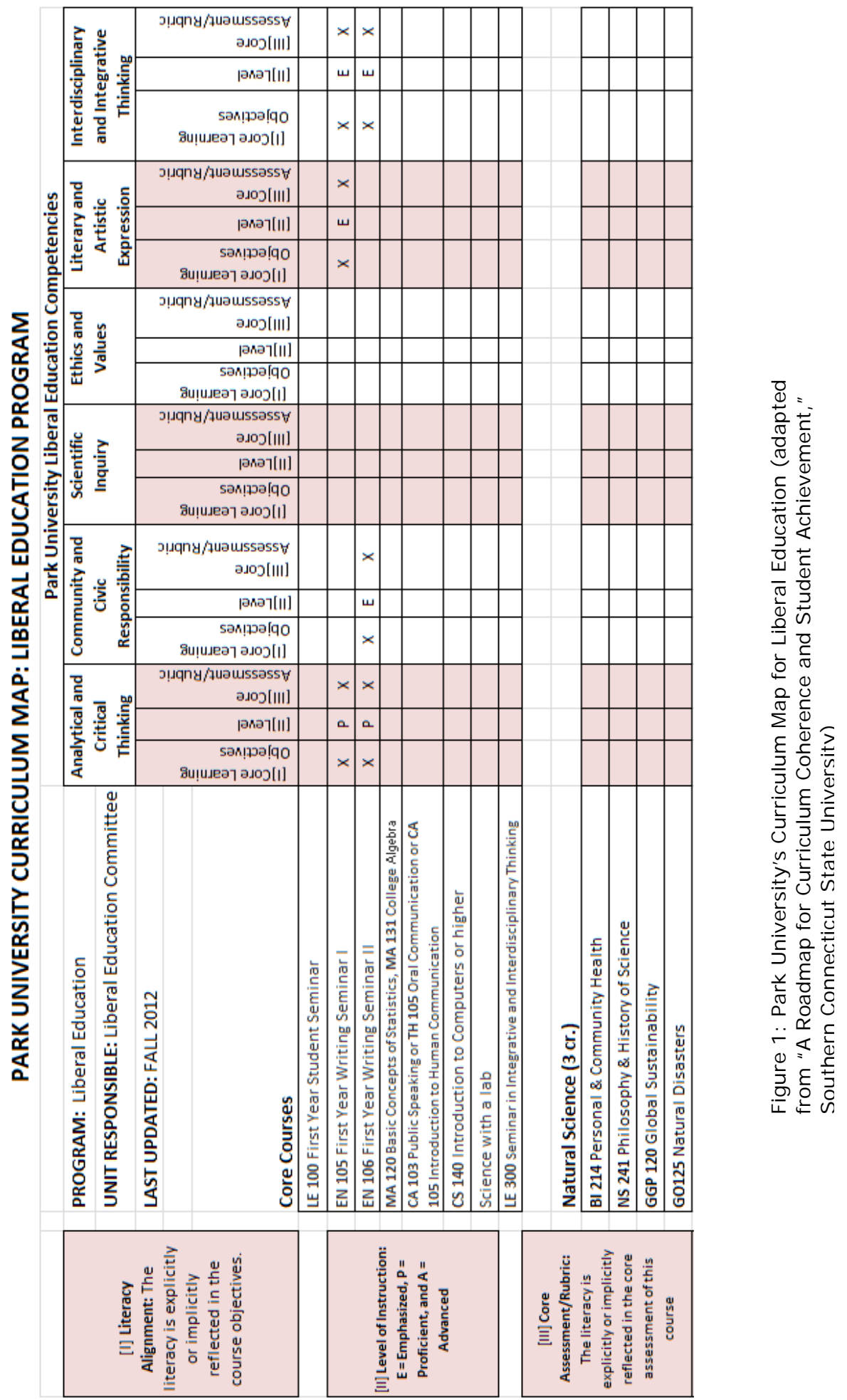
through its fierce attention to disciplinarity: "[D]isciplinary styles empower the scholarship of teaching, not only by giving scholars a ready-made way to image and present their work but also by giving shape to the problems they choose and the methods of inquiry they use" (Huber \& Morreale, 2002, p. 32).

One key influence of disciplinarity on the design of writing assessments in composition studies is the importance placed on global or "higher-order" concerns (focus, development, organization) over sentence-level or "lower-order" concerns (grammar, mechanics). At the start of the assessment project, we quickly encountered a conflict between this disciplinary value and the technology of the learning outcomes manager, and we modified the standard template based on a need to apply extra weight to some dimensions-certain skills and competenciesover others. Despite having developed a functional, weighted rubric, however, additional concerns, squarely based on disciplinary style, arose. Most notably, the institutional assessment model of identifying a single instrument - the writing portfolio/rubric - as the primary means of gauging student learning in the first-year composition courses chafed with our beliefs about disciplinary best practice. As expressed in the College Composition and Communication's position statement on the assessment of writing,

[i]deally, writing ability must be assessed by more than one piece of writing, in more than one genre, written on different occasions, for different audiences, and responded to and evaluated by multiple readers as part of a substantial and sustained writing process... Reflection by the writer on her or his own writing processes and performances holds particular promise as a way of generating knowledge about writing and increasing the ability to write successfully. ("Guiding Principle 3," emphasis added)

Although the writing portfolio typically contains, at minimum, five artifacts, including two essays, related evidence demonstrating student writing processes, and a reflective essay, the learning outcomes management rubric was best designed for assessment of a single artifact. Given the importance of student selfreflection to assessment in the discipline, then, we chose to leverage the outcomes manager software to work with the reflective essay. To address the disciplinary privileging of multiple "methods of inquiry" into teaching and learning, we collaboratively devised with our assessment partners a course map that would offer a more detailed, nuanced portrait of assessment in the courses, while still serving to align the courses with the University's general education outcomes. Importantly, the course map makes room for identification and articulation of a discipline-based rationale for multiple course assessments (Figure 2, shown on p. 56).

In order for institutional assessment to complement the scholarship of teaching and learning, both must operate within "a culture of teaching as intellectual work - work that can be theorized, work whose parameters and conditions of possibility can be analyzed and evaluated in accordance with formally articulated standards, work that can be interpreted within a framework of disciplinary knowledge and modes of inquiry" (Salvatori \& Donahue, 2002, p. 84). The course assessment map represents a move toward integrating discipline/department and institutional efforts, which holds potential to foster a culture of teaching and assessment as intellectual work. 


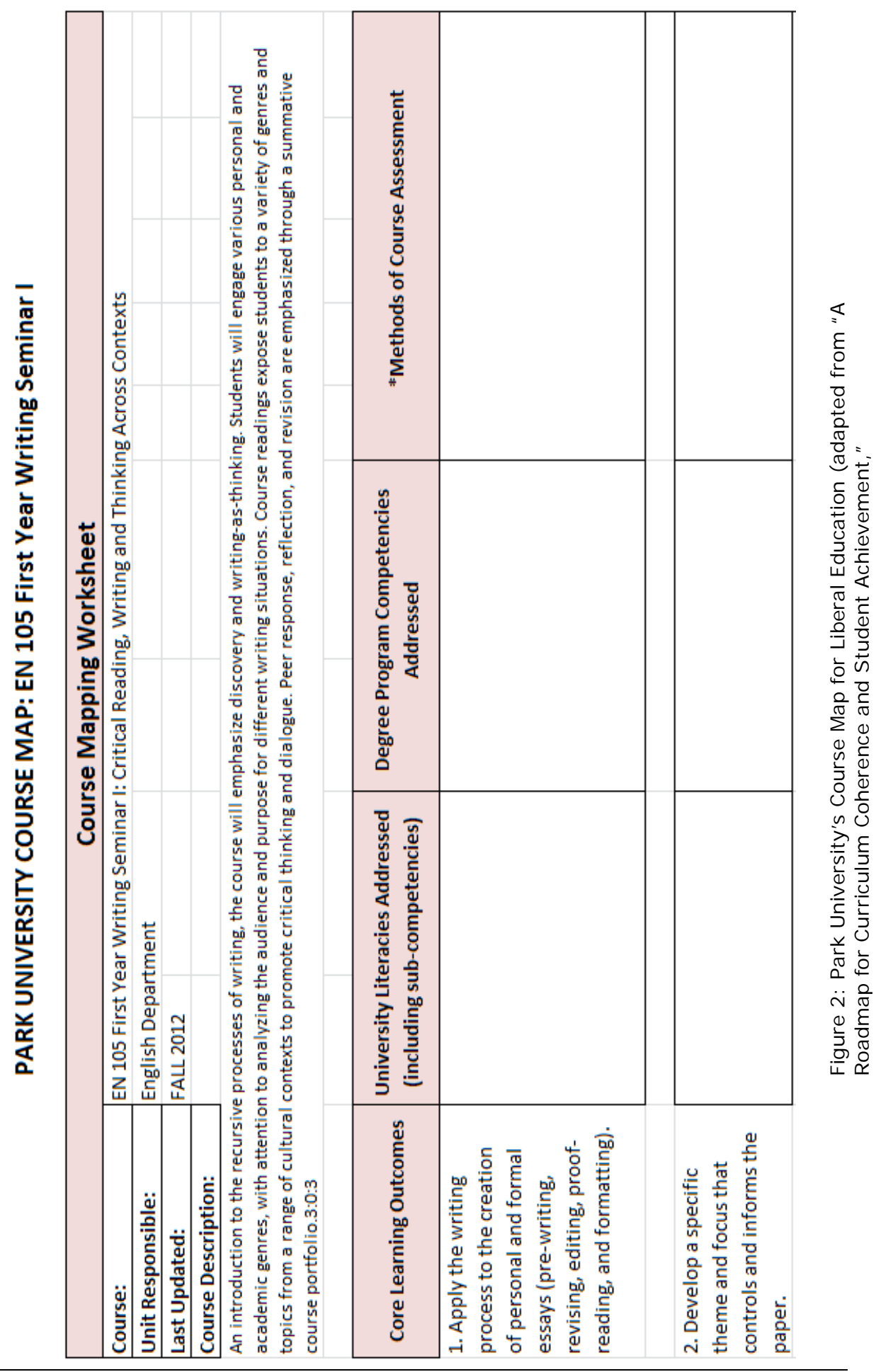




\section{Conclusion}

By tracing the shared "DNA" of the scholarship of teaching and learning and institutional assessment, Hutchings, Huber, and Ciccone (2011) reconcile two initiatives often perceived to be at odds. In reality, both movements "overlap around one deeply generative shared notion: that the experience and learning of college students can and should be a site for investigation; that there are good questions to be asked about what, how, how much, and how deeply students are learning" (p. 74). As the scholarship of teaching and learning foregrounds, how the investigation of student learning proceeds is highly contextualized within the disciplines. And as institutional assessment challenges, the private sphere of the classroom or discipline is necessarily joined and answerable to the institution, accrediting organizations, governmental bodies, and society at large. When placed into dialogue, these two initiatives can inform one another in ways that benefit student learning in the discipline and across the university.

\section{References}

Adler-Kassner, L., and O'Neill, P. (2010). Reframing writing assessment to improve teaching and learning. Logan: Utah State UP.

Broad, B., Adler-Kassner, L, Alford, B., Detweiler, J., Estrem, H., Harrington, S., McBride, M., Stalions, E., and Weeden, S. (2009). Organic writing assessment: Dynamic criteria mapping in action. Logan: Utah State UP.

College Composition and Communication. (2009). Writing assessment: A position statement. Retrieved from http://www.ncte.org/cccc/resources/ positions/writingassessment

Council of Writing Program Administrators. (2008). Outcomes statement for first-year composition. Retrieved from http://wpacouncil.org/files/wpaoutcomes-statement.pdf

Goodburn, A. (2002). (Re)viewing teaching as intellectual work in English studies: Insights from a peer review of teaching project. Reader: Essays in Reader-Oriented Theory, Criticism, and Pedagogy, 47, 83-108.
Howard, R.M., and Robillard, A.E. (Eds.). (2008). Pluralizing plagiarism: Identities, contexts, pedagogies. Portsmouth, NH: Heinemann Boynton/Cook.

Huber, M.T. and Morreale, S.P. (2002). Situating the scholarship of teaching and learning: A crossdisciplinary conversation. In M.T. Huber and S.P. Morreale (Eds.), Disciplinary styles in the scholarship of teaching and learning (pp. 1-24). Washington, DC: American Association for Higher Education and the Carnegie Foundation for the Advancement of Teaching.

Hutchings, P., Huber, M.T., and Ciccone, A. (2011). The scholarship of teaching and learning reconsidered: Institutional integration and impact. San Francisco: JosseyBass.

Salvatori, M.R., and Donahue, P. (2002). English studies in the scholarship of teaching. In M.T. Huber and S.P. Morreale (Eds.), Disciplinary styles in the scholarship of teaching and learning (pp. 69-86). Washington, DC: American

Association for Higher Education and The Carnegie Foundation for the Advancement of Teaching.

Sternglass, M., (1997). Time to know them: A longitudinal study of writing and learning. Mahwah, NJ: Erlbaum. 


\section{Author Note}

I wish to thank the Office of Academic Assessment at Park University for the opportunity to serve in a pilot program for learning outcomes manager implementation in spring 2013. I also wish to acknowledge and thank the members of the Liberal Education Assessment Taskforce at Park University with whom I collaborated in summer 2012 to propose an assessment plan for general education: Chad Ackerman, Steve Atkinson, Ken Christopher, Scott Hageman, Adam Potthast, and J ane Wood.

Emily Donnelli-Sallee, PhD, is an Associate Professor of English at Park University. She served as Program Coordinator for First-Year Writing from 2009-2012. Donnelli-Sallee teaches courses in writing and rhetoric, and she serves as editor of Missouri Campus Compact's J ournal of Public Scholarship in Higher Education. Her research examines the ways that public sphere theory can inform civic engagement pedagogies, particularly in first-year writing courses. Her work has appeared in Reflections: A Journal of Public Rhetoric, Civic Writing, and Service Learning; To Improve the Academy; and JAC: A Journal of Rhetoric, Culture, and Politics. Donnelli-Sallee earned her PhD in English from the University of Kansas. 